\title{
Histopathological analysis of the therapeutic response to cryotherapy with liquid nitrogen in patients with multiple actinic keratosis*
}

\author{
Marina Câmara de Oliveira ${ }^{1}$ \\ Clovis Antônio Lopes Pinto ${ }^{1}$ \\ Jaqueline Campoi Calvo Lopes Pinto ${ }^{1}$
}

\author{
Flávia Trevisan ${ }^{1}$ \\ Célia Antônia Xavier ${ }^{1}$
}

DOI: http:/ / dx.doi.org/10.1590/abd1806-4841.20153302

\begin{abstract}
Actinic keratoses are premalignant lesions of the skin caused by excessive sun exposure. Lesions may become mainly squamous cell carcinoma. Cryotherapy with liquid nitrogen is one of the main treatments. In order to evaluate the response of actinic keratosis to cryotherapy by histopathology, two lesions were selected in each of 14 patients with multiple actinic keratoses. In one lesion a biopsy was performed and in the other lesion a biopsy was performed after cryotherapy. Subsequently, both biopsies were compared histologically. Of the thirteen patients who completed the study, the best results were obtained in lesions undergoing cryotherapy concerning the atypia of keratinocytes, epithelial thickness and corneal layer and lymphocytic infiltrate. Despite the small number of patients, it was concluded that, if performed correctly, cryotherapy has high efficacy in the treatment of actinic keratoses.
\end{abstract}

Keywords: Cryotherapy; Histology; Keratosis, actinic

\section{INTRODUCTION}

Actinic keratoses are pre-malignant epithelial lesions induced by sensitivity to sun exposure associated with UVB radiation accumulation in the skin, which may cause keratinocyte mutations and progress to such lesions. ${ }^{1,2}$ Distribution depends on variables such as age, type of skin, sex, occupation, among others. The most affected body regions are related to the sun-exposed areas, such as head, neck and upper limbs. ${ }^{3}$ It is estimated that actinic keratoses represent the third most frequent reason for visiting a dermatologist. ${ }^{4}$

Actinic keratoses present themselves as unique or multiple keratotic papules or plaques with desquamation, erythematous or pigmented. Their borders may be poorly-defined and size may vary from two to six millimeters. ${ }^{3}$
Histologically, actinic keratoses are divided into six histological types: hypertrophic, acantholytic, atrophic, pigmented, lichenoid and bowenoid. The fundamental characteristic of an actinic keratosis is epithelial dysplasia, with atypical keratinocytes. ${ }^{5}$ There is variable loss of normal maturation processes, with abnormal keratinization. The epidermis presents areas with atrophy and acanthosis, characterized by hyperkeratosis and parakeratosis columns. In the superficial adjacent dermis, basophilic degeneration of collagen and elastosis is present, the latter being a strong marker of cumulative sun exposure. Almost always, there is also a perivascular lymphocitary inflammatory infiltrate. ${ }^{6,7}$

\footnotetext{
Received on 03.12.2013

Approved by the Advisory Board and accepted for publication on 27.02.2014

Work performed at the Dermatology Service da Faculdade de Medicina de Jundiaí (FMJ) - Jundiaí (SP), Brazil.

Financial Support: None.

Conflict of Interest: None.

Faculdade de Medicina de Jundiaí (FMJ) - Jundiaí (SP), Brazil.
}

C2015 by Anais Brasileiros de Dermatologia 
The meaning of these lesions corresponds to the risk of transformation into non-melanoma skin cancer, mainly squamous cell carcinoma. ${ }^{8}$ It is believed that there is gradual progression of chronically sun-exposed normal skin to actinic keratosis and afterwards to squamous cell carcinoma. ${ }^{2}$

Even though the diagnosis of actinic keratosis is basically clinical, eventually histological confirmation is necessary through analysis of biopsy fragments of the cutaneous lesion, as in situations of doubt about thickening, infiltration, bleeding, ulceration and also when there is lesion recurrence or persistence even after treatment. ${ }^{3,9}$

Although malignancy rates are low, it is recommended that actinic keratosis be treated, due to the difficulty in establishing which lesions will progress to squamous cell carcinoma. The treatment options are varied. Treatment may be subdivided into two categories, the isolated lesions and field cancerization. ${ }^{10}$ Field cancerization treatment importance has increasingly been recognized for patients with multiple lesions and important photodamage and may be combined with the isolated treatment of lesions. ${ }^{10}$ In the 2010 guidelines for managing actinic keratoses, the therapies described for isolated and smaller lesions include ablative procedures such as cryotherapy/cryosurgery, curettage, laser ablation and surgery. ${ }^{11}$ Topical treatments, such as photodynamic therapy, 5-fluorouracil, diclofenac gel and imiquimod can be very useful both in treating lesions individually and in field cancerization treatment. All techniques demonstrate efficacy and different adverse effects, for example, discomfort, slow cicatrization and pigmentation changes, and their choice depends on duration and course of lesions, site and duration of disease, presence of single or multiple lesions, age, comorbidities, mental conditions and patient adherence, skin cancer history and presence of risk factors, mainly immunosuppression. ${ }^{5,10-12}$

Cryotherapy with liquid nitrogen is one of the most used treatments since it is of easy application, may be used in the medical office, absence of bleeding, possibility of waiving anesthesia and good results. The technique consists in spraying nitrogen directly over lesions through a cryospray, catheter or with the help of a swab. When liquid nitrogen comes in contact with the skin through spray or catheter, the temperature of the area reaches $-196^{\circ} \mathrm{C}$. Freezing of skin may reach a depth of 10 millimeters, depending on duration and distance of application. ${ }^{12,13}$

Due to quick freezing, there is cell death and tissue necrosis. Collagen fibers and cartilages are resistant to freezing, which is paramount to cicatrization. ${ }^{14}$ Some authors claim that cryotherapy must be used from 5 to 10 seconds over and around each lesion, with longer times for thicker lesions. However, others believe that it is necessary to freeze lesions for a minimum of 10 seconds and a maximum of 15 seconds, to avoid undesired secondary effects. ${ }^{1}$

The indication for cryotherapy treatment considers the size and type of the lesion, its site and whether it is recurrent. It is contraindicated for poorly delimited and cicatricial lesions and for patients suffering from urticaria and intolerance to cold, such as patients with Raynaud's disease. ${ }^{12,13}$ Thicker lesions and those located on dorsum of hands are prone to be more resilient. ${ }^{11}$

The disadvantages of the procedure are related to discomfort, formation of crusts, vesiculae and blisters that may remain up to 10 days after the procedure, the inability of treating wide areas and the risk of hypopigmentation. Some authors reported that $29 \%$ of hypopigmentations were directly related to freezing time. ${ }^{12,13,15,16}$ However, among the advantages of cryotherapy is the independence of patient adhesion to prolonged use of topical treatments, the agility, cost and efficacy of the procedure, which achieves 75-99\% when the technique is correctly used. ${ }^{16}$

The objective of this study was to evaluate histopathological changes in actinic keratoses in patients who underwent cryotherapy and evaluate the response to therapies through a comparative study of clinical and histopathological data.

\section{MATERIAL AND METHODS}

For this study, during the period of August 2012 to January 2013, 16 patients were selected from the dermatology outpatient clinic at the Medical School of Jundiaí (Faculdade de Medicina de Jundiaí) Jundiaí, São Paulo. Seven were male and nine female, aged between 43 and 82, who had been clinically diagnosed with a minimum of two actinic keratoses on the upper limbs, with a history of previous treatments and persistence of lesions, whether considered new or recurrent and who agreed to participate in the study. The following inclusion criteria were used in the selection: patients should be already monitored at the outpatient clinic of the institution, have a clinical diagnosis of multiple actinic keratoses (more than two) on upper limbs, previous topical or cryotherapic treatment with recurrent and/ or new lesions, regular use of sunscreen with SPF 30 or more, acceptance, authorization and signature of the informed consent form, return for completion of study and performing two biopsies. The exclusion criteria were: history of severe comorbidities, history of vascular and microcirculation disorders (diabetes, for example), history of coagulation disorders or use of drugs that alter coagulation, absence of signature of the informed consent form, express desire of not participating in the study, and no authorization for the utilization of the analyzed data. All ethical prin- 
ciples for research involving human beings according to the Declaration of Helsinki were followed.

In each of the 16 patients, two similar lesions with clinical and dermoscopic diagnosis of actinic keratosis were selected, named randomly as lesion (1) and (2). Both were recorded photographically following standard camera distance, zoom and coordinates in centimeters. In lesion (1), a central punch biopsy of four millimeters was performed. In lesion (2), cryotherapy was applied with liquid nitrogen in cryospray, with no previous anesthesia, for ten seconds.

After a period of 30 days, the patients returned so that lesion (2), submitted to cryotherapy, could also be biopsied and compared to lesion (1), previously biopsied. Only 14 patients returned to the clinic for this new biopsy.

Biopsies were sent to the Pathology laboratory of the institution, responsible for histological processing. Histological sections of $3 \mu \mathrm{m}$ were performed on tissue immersed in paraffin and stained by hematoxilin-eosin method. A pathologist physician performed the histopathological analysis using an Olympus BX41 optical microscope and making photographic records of the main histological changes found.

The findings of identified changes were qualified and quantified according to criteria defined by the main histological changes described in actinic keratosis, which are: keratinocyte atypia, epithelium thickness, elastosis thickness, lymphocitary infiltrate and corneal layer thickness. Based on these parameters, a subjective method was defined to classify findings as marked, moderate, slight or absent. This method aimed to evaluate and classify lesions (1) and (2) separately and later on compare the results obtained, in an attempt to make the comparison as objective as possible. Histological comparison of alterations was non blind and was done by a single experienced pathologist.

\section{RESULTS}

During the histopathological analysis of lesions a squamous cell carcinoma was diagnosed in one of the lesions in situ. Since clinically such lesion was similar to actinic keratosis, it was included in the study in the beginning, but then it was not possible to histologically analyze the predefined criteria due to presence of other alterations, so both biopsies were excluded from the analyses and thirteen patients remained to be analyzed.

From this study it was possible to observe that the average age of greatest occurrence of actinic keratoses was 70.3. All patients selected stated they had had excessive solar exposure in the past and denied using sunscreen regularly. Moreover, in the thirteen participating patients, the site of greatest involvement of lesions was on upper limbs.

The following changes were found (Table 1 and 2):

- Atypia of keratinocytes (Figure 1): ten patients $(76.92 \%)$ of thirteen studied showed smaller degree of atypia in lesions with cryotherapy. On the other hand, three patients $(23.07 \%)$ showed similar degrees of atypia between treated and non-treated lesions.

- Epithelium thickness: of thirteen patients, nine $(69.23 \%)$ presented a thinner epithelium in the treated lesion, whereas four patients $(30.76 \%)$ presented a thinner epithelium in the lesion that was not treated.

TABLE 1: Histopathological criteria evaluated in thirteen patients of this study, pre and post cryotherapy

\begin{tabular}{|c|c|c|c|c|c|c|c|c|c|c|}
\hline \multirow[t]{2}{*}{ Ptnt } & \multicolumn{2}{|c|}{ Atypia } & \multicolumn{2}{|c|}{ Epidermis } & \multicolumn{2}{|c|}{ Cornea } & \multicolumn{2}{|c|}{ Elastosis } & \multicolumn{2}{|c|}{ Infiltrate } \\
\hline & Pre & Post & Pre & Post & Pre & Post & Pre & Post & Pre & Post \\
\hline 1 & $\mathrm{M}$ & $\mathrm{L}$ & 0.13 & 0.10 & 0.60 & 0.05 & 0.30 & 0.55 & $\mathrm{M}$ & $\mathrm{A}$ \\
\hline 2 & $\mathrm{~A}$ & A & 0.17 & 0.10 & 0.20 & 0.15 & 0.30 & 0.13 & $\mathrm{M}$ & A \\
\hline 3 & $\mathrm{M}$ & $\mathrm{L}$ & 0.10 & 0.08 & 0.10 & 0.05 & 0.45 & 0.40 & $\mathrm{M}$ & $\mathrm{M}$ \\
\hline 4 & $\mathrm{~L}$ & $\mathrm{~L}$ & 0.06 & 0.19 & 0.10 & 0.20 & 0.52 & 0.50 & A & A \\
\hline 5 & $\mathrm{M}$ & $\mathrm{L}$ & 0.55 & 0.08 & 0.50 & 0.05 & 1.00 & 2.00 & $\mathrm{M}$ & A \\
\hline 6 & $\mathrm{~L}$ & $\mathrm{~L}$ & 0.10 & 0.05 & 0.05 & 0.05 & 0.20 & 0.25 & A & A \\
\hline 7 & $\mathrm{M}$ & $\mathrm{L}$ & 0.15 & 0.06 & 0.45 & 0.15 & 0.65 & 0.90 & I & $\mathrm{L}$ \\
\hline 8 & $\mathrm{M}$ & A & 0.45 & 0.20 & 0.33 & 0.01 & 1.10 & 1.00 & $\mathrm{~L}$ & A \\
\hline 9 & $\mathrm{M}$ & $\mathrm{M}$ & 0.20 & 0.31 & 0.25 & 0.30 & 1.20 & 1.00 & $\mathrm{M}$ & $\mathrm{M}$ \\
\hline 10 & $\mathrm{~L}$ & A & 0.12 & 0.22 & 0.22 & 0.25 & 0.40 & 0.50 & $\mathrm{~L}$ & A \\
\hline 11 & I & $\mathrm{L}$ & 0.40 & 0.21 & 0.25 & 0.10 & 0.00 & 0.00 & $\mathrm{M}$ & A \\
\hline 12 & $\mathrm{M}$ & A & 0.28 & 0.20 & 0.23 & 0.15 & 0.30 & 1.50 & I & A \\
\hline 13 & $\mathrm{M}$ & $\mathrm{L}$ & 0.35 & 0.36 & 0.45 & 0.35 & 0.30 & 0.55 & $\mathrm{~L}$ & A \\
\hline
\end{tabular}

\footnotetext{
Ptnt: patient. A: absent. L: light. M: moderate. I: intense.
} 
- Thickness of the corneal layer: of thirteen patients, nine $(69.23 \%)$ presented smaller thickness in lesions treated with cryotherapy. Three of them $(23.07 \%)$ presented smaller thickness in lesions that were not treated, whilst one $(7.69 \%)$ presented similar thickness for the two lesions.

- Thickness of elastosis: only twelve patients had actinic elastosis in the dermal layer. Out of these, five $(41.66 \%)$ presented less elastosis in the lesion which underwent cryotherapy and seven (58.33\%) had less elastosis in the non-treated lesion.

- Lymphocitary infiltrate: out of thirteen patients, two $(15.38 \%)$ did not have a lymphocitary infiltrate. Regarding the eleven patients that had it, nine $(81.81 \%)$ presented a better degree of lymphocitary infiltrate in lesions that were submitted to treatment in comparison to the non-treated ones. Two patients $(18.18 \%)$ presented the same degree of infiltrate in both lesions.

\section{DISCUSSION E CONCLUSION}

Actinic keratoses are today one of the main and more constant skin lesions seen by dermatologists. ${ }^{4}$ Between 40 and 65 years of age, it is the third most prevalent dermatologic disease. For those over 65 it is the first one. Its prevalence may increase up to $80 \%$ in people over $70 .{ }^{3}$ Its onset is related with the sites of photoexposure, as its pathogenesis is initiated with exposure to UVB rays. ${ }^{1}$

The presence of multiple keratoses in photoexposed areas results in areas prone to formation of non-melanoma skin cancers, called field cancerization. Thus, the importance of diagnosis and correct management of actinic keratoses has gained new strength and a new point of view. ${ }^{17}$ Latest research has shown the need for treatment of clinical lesions as well as of subclinical ones, for areas apparently without lesions may contain histopathological and genetic alterations that may evolve to malignization. ${ }^{10}$

TABle 2: Percentage of cases for each analyzed criterium

\begin{tabular}{lcc}
\hline Criteria & $\begin{array}{l}\text { Percentage of cases with } \\
\text { provement after cryotherapy }\end{array}$ & $\begin{array}{l}\text { Percentage of cases with im } \\
\text { absent criterium }\end{array}$ \\
\hline Atypia of keratinocytes & 76.92 & 0 \\
Thickness of epithelium & 69.23 & 0 \\
Thickness of cornea & 69.23 & 0 \\
Thickness of elastosis & 33.93 & 7.69 \\
Lymphocitary infiltrate & 69.23 & 15.38 \\
\hline
\end{tabular}
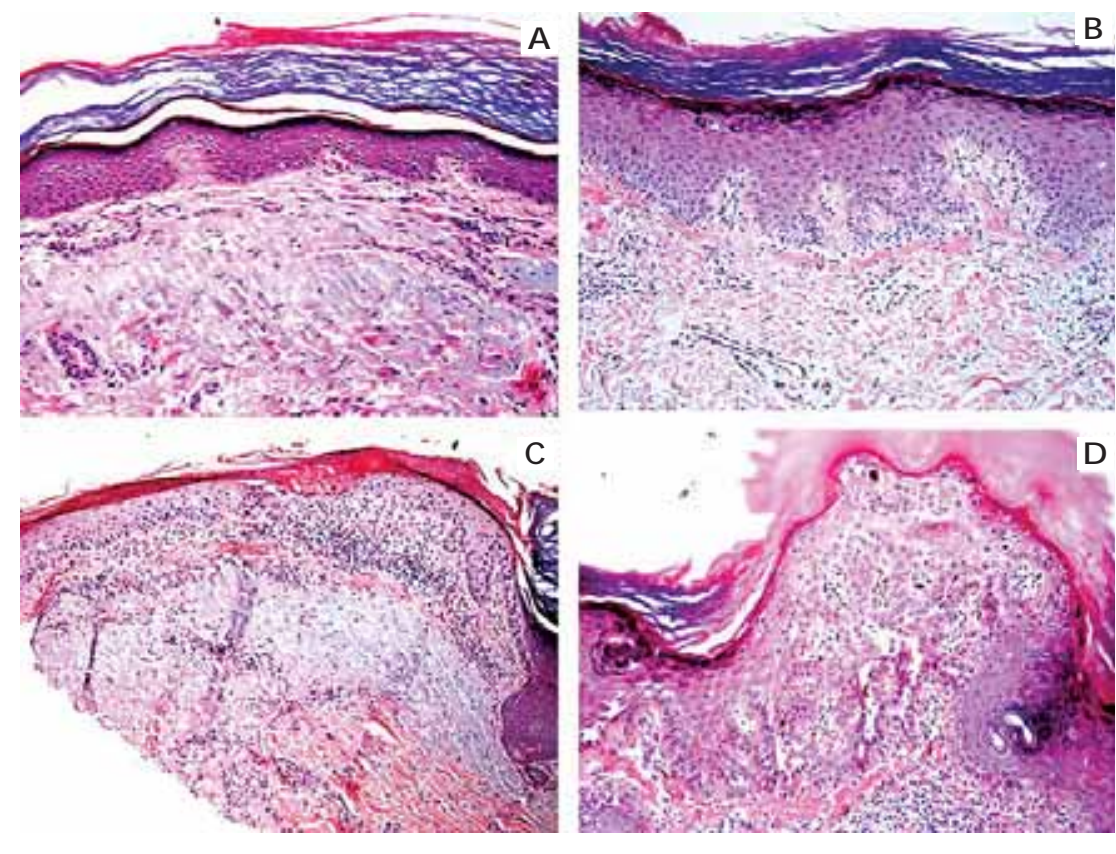

\section{Figure 1:}

Levels of atypia of keratinocytes: A. No atypia. B. Light atypia. C. Moderate atypia. D. Intense atypia 
Diagnosis of keratoses is basically clinical, and need for a biopsy is rare. ${ }^{3,9}$ However, some lesions may be very similar to squamous cell carcinomas. In a study, the clinical-histopathological correlation of lesions was $91 \%$, suggesting that one in 25 lesions clinically diagnosed as actinic keratosis was in fact initial SCCs in histological analysis. ${ }^{3}$ This can be seen in this study, since a case of a lesion clinically diagnosed as actinic keratosis was found which, in the histopathological analysis, revealed itself to be a squamous cell carcinoma in situ.

A study demonstrated cure of $67 \%$ of lesions treated with cryotherapy, analyzed three months later. In another study, freezing time varied between five and twenty seconds, which may have influenced the cure rate of each lesion since with a freezing time of five seconds the cure rate was 39\%, whereas with a freezing time of twenty seconds the rate was $83 \%{ }^{3}$

In this study we observed that the involvement of actinic keratosis does not predominate in any gender, being equally distributed between men and women. The age bracket variable presented old age, indicating that the disease is directly related to cumulative exposure of skin to UV radiation. The most common site for lesions in photoexposed regions was in agreement with the data in literature. All patients in the study reported excessive sun exposure in the past without wearing sunscreen.

Clinical improvement of actinic keratoses is visible and perceived in routine practice of dermatologists (Figure 2). Application time of cryotherapy was determined based on literature, which indicates five to ten seconds spraying is necessary for thin lesions.

This study showed great technical difficulty in evaluating the same lesions before and after cryotherapic treatment, which would be ideal. Notwithstanding, the majority of lesions was small and the inflammation triggered during the cicatrization of an incisional biopsy could be a confounding factor in the analysis of histopathological symptoms. In addition to this difficulty, there is still the possibility that the lesion treated initially, without previous biopsy, would present histopathological changes which would be characterized as SCC in situ or with signs of microinvasion, even presenting itself clinically as pre-malignant. To circumvent this bias, the initial dermoscopic and clinical analysis was very thorough, in an attempt to choose two lesions as similar as possible. These important limitations were also partially minimized by positive results, for even if lesions were malignant, most of them presented regression in biopsy 30 days after cryotherapy.

A third bias was the fact that the evaluation and comparison of histological changes had been subjective, not blind and done by a single pathologist.
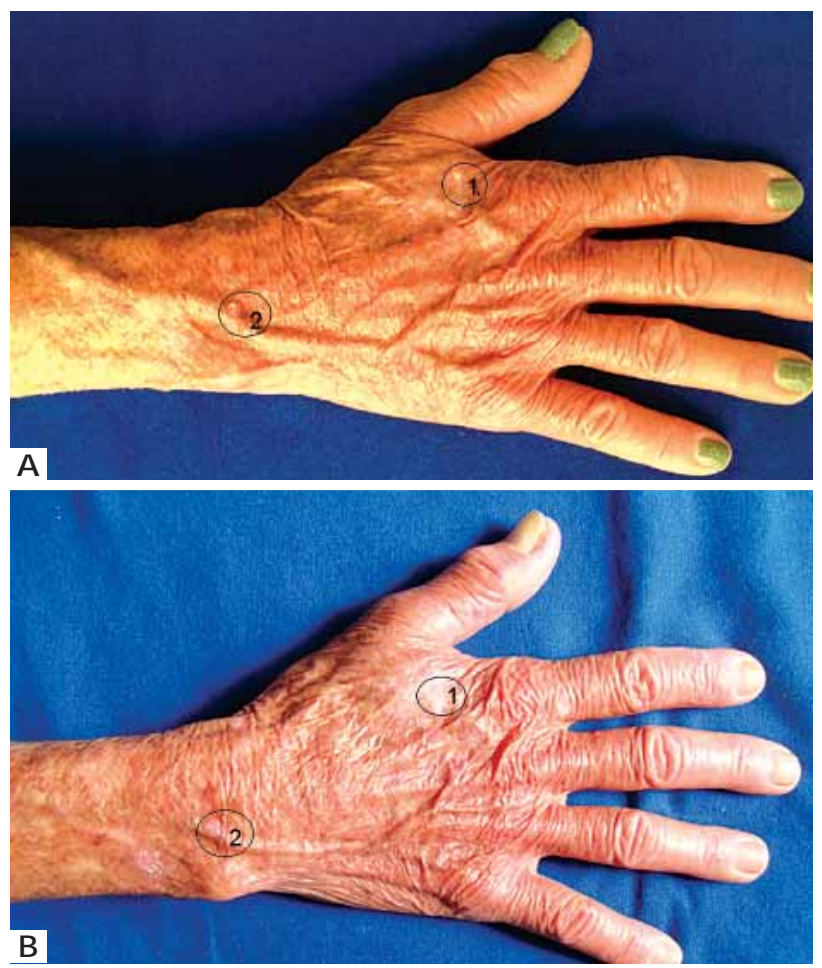

Figure 2: Pre-treatment (A) and post-treatment (B) lesions: lesion 1 submitted to cryotherapy and lesion 2 submitted to biopsy

Of the five established evaluation criteria, only one showed worsening in more than $50 \%$ of the studied cases, which was elastosis thickness. This points out that probably for this criterium other liquid nitrogen or applications with longer durations would be necessary. Keratin works as a thermal insulator, which may diminish the effect of cryotherapy in thicker lesions such as hypertrophic actinic keratoses. Thus, the association of cryotherapy with curettage or debridement of lesion may be useful.

Treatment of pre-malignant lesions separately and in combination with the cancerization field treatment must be prioritized. Good suggestions of association of treatments would be photodynamic therapy or 5-fluorouracil for field cancerization and ablative laser or cryotherapy for isolated lesions. For isolated lesions, cryotherapy is still one of the methods of choice due to its ease and wide experience of dermatologists with the technique.

Generally, in spite of the small number of patients, the results of the study were in accordance with data in the literature. These results allow us to assume that cryotherapy can be applied in isolated regions, clinically diagnosed with actinic keratoses, causing a good response confirmed by histological analysis with improvement of analyzed criteria, after one application. $\square$ 


\section{REFERENCE}

1. Goldberg LH, Kaplan B, Vergilis-Kalner I, Landau J. Liquid Nitrogen: Temperature Control in the Treatment of Actinic Keratoses. Dermatol Surg. 2010;36:1956-61.

2. Ra SH, Li X, Binder S. Molecular discrimination of cutaneous squamous cell carcinoma from actinic keratoses and normal skin. Mod Pathol. 2011;24:963-73.

3. Webber, A. Estudo comparativo entre terapia fotodinâmica e imiquimod tópico para tratamento de ceratoses actínicas. [dissertação]. Porto Alegre (RS): Universidade Federal do Rio Grande do Sul; 2009.

4. Muston D, Downs A, Rives V. An economic evaluation of topical treatments for actinic keratoses. J Dermatolog Treat. 2009;20:266-75.

5. de Berker D, McGregor JM, Hughes BR; British Association of Dermatologists Therapy Guidelines and Audit Subcommittee. Guidelines for the management of actinic keratoses. Br J Dermatol. 2007;156:222-30.

6. Roewert-Huber J, Stockfleth E, Kerl H. Pathology and pathobiology of actinic (solar) keratoses - an update. Br J Dermatol. 2007;157:18-20.

7. Cho CG, Jo HY, Choi HC, Kim IH, Song HJ, Oh CH. A Study of the solar effect on actinic keratoses by quantification of elastic fibers using an image analysis system. Acta Derm Venereol. 1999;79:278-80.

8. Cohen, J. L. Actinic keratoses treatment as a key component of preventive strategies for nonmelanoma skin cancer. J Clin Aesthet Dermatol. 2010;3:39-44.

9. Dornelas MT, Rodrigues MF, Machado DC, Gollner AM, Ferreira AP. Expression of cell proliferation and apoptosis biomarkers in skin spinocellular carcinoma and actinic keratose. An Bras Dermatol. 2009;84:469-75.

10. Torezan LA, Festa-Neto C. Campo de cancerização cutâneo: implicações clínicas, histopatológicas e terapêuticas. An Bras Dermatol. 2013;88:775-86.

11. Stockfleth E, Terhost D, Braathen L, Cribier B, Cerio R, Ferrandiz C, et al. Guidelines for the management of Actinic Keratoses. European Dermatology Forum, 2011, Berlin, Germany. [Internet]. Disponível em: http://www.euroderm.org/images/ stories/guidelines/guideline_Management_Actinic_Keratoses-update2011.pdf.

12. Martin, G. The impact of the current United States guidelines on the management of actinic keratoses: is it time for an update? J Clin Aesthet Dermatol. 2010;3:20-5.

13. Kuflik EG, Gage AA. Cryobiology. Cryosurgical treatment for skin cancer. New York: Igaku-shoin; 1990. p 266.

14. Dawber R, Colver G, Jackson A. Criocirurgia cutânea - Princípios e prática clínica. São Paulo: Manole; 1999. p 135

15. Moraes AM, Velho PENF, Magalhães RF. Cryosurgery using liquid nitrogen and infectious skin diseases. An Bras Dermatol. 2008;83:285-98.

16. Berlin JM. Current and emerging treatment strategies for the treatment of actinic keratoses. Clin Cosmet Investig Dermatol. 2010;3:119-26.

17. Ibrahim SF, Brown MD. Actinic Keratoses: a comprehensive update. J Clin Aesthet Dermatol. 2009;2:43-8.
M AILING ADDRESS:

Flávia Trevisan

Rua Francisco Telles, 250 - Vila A rens

13202250 - Jundiaí - SP

Brazil

E-mail: flaviatrevisan1@gmail.com

How to cite this article: Oliveira MC, Trevisan F, Pinto CAL, Xavier CA, Pinto JCCL. Histopathological analysis of the therapeutic response to cryotherapy with liquid nitrogen in patients with multiple actinic keratoses. An Bras Dermatol. 2015; 90(3):384-9. 